\title{
Partial Generalization in Pigeons Trained to Discriminate Morphine From Saline: Applications of Receptor Theory
}

\author{
Wouter Koek and James H. Woods
}

Department of Pharmacology, The University of Michigan, Ann Arbor

\begin{abstract}
Koek, W., and J.H. Woods: Partial generalization in pigeons trained to discriminate morphine from saline: Applications of receptor theory. Drug Dev. Res. 16:169-181, 1989.

In pigeons trained to discriminate $5.6 \mathrm{mg} / \mathrm{kg}$ of morphine from saline, cyclazocine, I-N-allyl-normetazocine (I-NANM, I-SKF10,047), and ketamine, but not U50,488, produced partial generalization, i.e., a maximum level of drug-appropriate responding between the levels produced by saline and by the training drug. The generalization gradient of cyclazocine and of I-NANM, but not that of ketamine, was less steep than the gradient of morphine. Cyclazocine and I-NANM, but not U50,488 and ketamine, antagonized partially the discriminative stimulus (DS) effects of morphine. Naltrexone antagonized the DS effects of morphine, cyclazocine, and I-NANM, but not ketamine. Increasing the training dose of morphine shifted the morphine gradient to the right, increased the antagonist effects of cyclazocine and of I-NANM, and decreased their agonist effects, but did not alter the effects of ketamine. Decreasing the training dose of morphine shifted the morphine gradient to the left and increased the agonist effects of cyclazocine, but did not alter the effects of I-NANM and ketamine. The full generalization produced by cyclazocine when the training dose of morphine was lowered could be blocked completely by naltrexone and I-NANM, but not by ketamine. These results suggest that cyclazocine and I-NANM, but not ketamine, produced partial generalization because of their low efficacy at the receptor that underlies the DS effects of morphine. However, the results obtained with ketamine suggest that partial generalization may also be produced through other mechanisms.
\end{abstract}

Key words: drug discrimination, partial agonist, efficacy, opioids, phencyclidine, cyclazocine, I-N-allylnormetazocine (I-SKF10,047), U50,488, ketamine

Received final version August 29, 1988; accepted September 6, 1988.

Address reprint requests to Wouter Koek, Ph.D., Neurobiology Division, FONDAX-Groupe de Recherche SERVIER, 7 Rue Amperc, F-92800 Puteaux, France.

(C) 1989 Alan R. Liss, Inc. 


\section{INTRODUCTION}

In a typical drug discrimination procedure, animals are trained to emit one response following the administration of a drug and a different response following the administration of saline. In general, animals will emit drug-appropriate responses only when tested with novel compounds that are pharmacologically similar to the training drug. For example, morphinetrained animals will typically show full drug-appropriate responding only when tested with other opioids. Certain test drugs, however, produce some, but not full, drug-appropriate responding. Such drugs are said to produce partial generalization, i.c., a maximum level of drug-appropriate responding between the levels produced by saline and by the training drug. Receptor theory has guided the analysis of partial generalization data [e.g., Colpaert et al., 1982; Colpaert and Janssen, 1984; Holtzman, 1983; Woods et al., 1988].

According to receptor theory [e.g., Kenakin, 1987], drugs have two basic properties: the ability to bind to receptors, referred to as affinity, and the ability to stimulate receptors, variously referred to as intrinsic activity, efficacy, or intrinsic efficacy. Partial generalization can conceivably result from: 1) low efficacy at the receptor that underlies the discriminative stimulus effects of the training drug; 2) actions at other receptors; or 3) nonreceptor-mediated actions. It may be helpful to assume initially that drugs produce partial generalization because they possess less efficacy than the training drug [e.g., Colpaert, 1986, 1988; Woods ct al., 1988]. In accordance with receptor theory, the following predictions can be derived from this assumption:

1. The generalization gradient of a low-efficacy agonist is less steep than the generalization gradient of the training drug.

2. A low-efficacy agonist partially antagonizes the discriminative stimulus effects of the training drug, in the dose range in which the low-efficacy agonist produces partial generalization when given alone.

3. The partial generalization produced by a low-efficacy agonist is blocked by a competitive antagonist of the discriminative stimulus effects of the training drug.

4. A low-efficacy drug can be a full agonist, a partial agonist, or an antagonist, depending on the sensitivity of the test system. The apparent sensitivity of a drug discrimination can be altered by varying the training dose. Increasing the training dose decreases the sensitivity to the effects of the training drug and of drugs that produce full drug-appropriate responding; conversely, decreasing the training dose increases the sensitivity of the discrimination [e.g., Colpaert et al., 1980; Holtzman, 1982; Koek and Slangen, 1982]. Therefore a low-efficacy agonist will produce less generalization and more antagonism of the effects of the training drug as the training dose is increased, and will produce more generalization and less antagonism of the training drug as the training dose is decreased.

5. The discriminative stimulus effects of a low-efficacy agonist can be blocked by another, less efficacious agonist

Cyclazocine produces partial generalization in morphine- and in fentanyl-discriminating animals [e.g., Holtzman, 1983; Colpaert and Janssen, 1984; Paule and Wenger, 1986]. In agreement with the assumption that cyclazocine produced partial generalization because of its low eflicacy at the receptor that mediates the discriminative stimulus effects of morphine and of fentanyl, this partial generalization has been shown to have some of the above-mentioned characteristics. To replicate and extend these findings, we studied the ability of cyclazocine to produce partial generalization in pigeons that were trained to discriminate between morphine and saline and tested each of the five aforementioned predictions.

In addition to cyclazocine, the selective kappa-opioid receptor agonist U50,488, the 1-isomer of N-allyl-normetazocine (NANM, SKF10,047) and the phencyclidine (PCP)-like drug, ketamine, were studied: 1) to explore whether they also produced partial generalization; 
and 2) to analyze their partial generalization effects, if any, by testing the aforementioned predictions. U50,488 and ketamine were included because they have been reported to produce partial generalization in morphine-discriminating pigeons [Essman and Woods, 1986; Herling et al., 1980]; I-NANM was included because preliminary experiments suggested that it produced substantial, but less than maximal, morphine-appropriate responding.

\section{MATERIALS AND METHODS Subjects}

Six experimentally naive White Carneaux pigeons (Palmetto, Sumter, SC) were housed individually with water and grit freely available and were maintained at $80 \%$ of their free-feeding weight by providing mixed grain in the home cage after each experimental session.

\section{Apparatus}

Six ventilated, sound-attenuated chambers measuring $36 \times 28 \times 33 \mathrm{~cm}$ werc used. Three translucent response keys, $2.4 \mathrm{~cm}$ in diameter, were located on the inside of one wall, $25 \mathrm{~cm}$ from the chamber floor. The keys were $5 \mathrm{~cm}$ from each other and could be transilluminated by red $7-\mathrm{W}$ lights located behind the wall. Mixed grain was made available for reinforcement by means of a hopper, below the center response key and $10 \mathrm{~cm}$ above the floor of the chamber. A Texas Instruments Inc. (Dallas, TX) 960A computer, located in an adjacent room, was used for programming and data collection.

\section{Procedure}

After autoshaping of a key-peck response, the pigeons were trained to discriminate an IM injection of $5.6 \mathrm{mg} / \mathrm{kg}$ of morphine from saline. Training sessions were conducted 7 days/week. Each session was preceded by an injection of either the training drug or saline, after which the pigeon was placed in the experimental chamber. After $10 \mathrm{~min}$, during which the chamber was dark and key-peck responses had no programmed consequences, the house light came on, and the left and the right key were illuminated red. During the first two to three sessions saline was administered, and responses on the right key resulted in 4-sec access to mixed grain, according to a reinforcement schedule that was gradually changed from fixed ratio (FR) 1 to FR 20. The key lights were off during food presentation, and a white light illuminated the hopper. A session ended after 50 reinforcements, or after $1 \mathrm{~h}$, whichever occurred first. During the next two to three sessions the training drug was administered, responses on the left key were reinforced, and the reinforcement schedule was changed from FR 1 to FR 20. Thereafter, drug and saline sessions alternated according to a doublealternation sequence. Twenty responses on the injection-appropriate key (i.e., left key drug-appropriate, right key saline-appropriate) resulted in reinforcement. Responses on the inappropriate key had no programmed consequences. Training was continued until less than five responses were made on the injection-inappropriate key, before the first food presentation, during ten consecutive sessions. When this training criterion was met, test sessions $(T)$ and drug (D) and saline (S) training sessions were conducted according to two sequences (alternating weekly): S-D-T-S-T-D-T and D-S-T-S-T-D-T, A test session ended, without reinforcement, when 20 responses had been made on either key, or after $1 \mathrm{~h}$, whichever occurred first. The key on which 20 responses accumulated first was defined as the selected key [i.e., drug key (DK) or saline key (SK)].

Tests were conducted only if the injection-appropriate key was selected during both the immediately preceding drug training session and saline training session; otherwise drug and saline training sessions were alternated until the appropriate key was selected during two consecutive sessions. 
Different doses of morphine and of cyclazocine were tested twice, in the following order: morphine-cyclazocine-morphine-cyclazocine. Next, the ability of naltrexone to antagonize DK selection produced by the training dose of morphine (i.e., $5.6 \mathrm{mg} / \mathrm{kg}$ ) was evaluated by injecting different doses of naltrexone $15 \mathrm{~min}$ before the injection of $5.6 \mathrm{mg} / \mathrm{kg}$ of morphine. In addition, I-NANM, ketamine, U50,488, and naltrexone were tested for their ability to produce DK selection, and cyclazocine, 1-NANM, ketamine, and U50,488 were tested for their ability to antagonize DK selection produced by the training dose of morphine. Finally, the effects of naltrexone on cyclazocine-, l-NANM-, and ketamine-induced DK selection were tested. At this point in the study, one of the pigeons died.

In two of the remaining five pigeons, the training dose of morphine was increased from 5.6 to $10 \mathrm{mg} / \mathrm{kg}$ and, after the discrimination criterion was met, was increased further to 18 $\mathrm{mg} / \mathrm{kg}$. In the other three pigeons, the training dose of morphine was lowered from $5.6 \mathrm{mg} / \mathrm{kg}$ via $3.2 \mathrm{mg} / \mathrm{kg}$ to $1.8 \mathrm{mg} / \mathrm{kg}$. Pigeons that discriminated $18 \mathrm{mg} / \mathrm{kg}$ of morphine were tested with morphine, were tested (with naltrexone as a pretreatment to morphine) and were tested with cyclazocine, l-NANM, and ketamine alone and as pretreatment to morphine. In the pigeons that discriminated $1.8 \mathrm{mg} / \mathrm{kg}$ of morphine, different doses of morphine, cyclazocine, 1-NANM, and ketamine were tested for their ability to produce DK selection, and naltrexone was tested for its ability to antagonize morphine-induced DK selection. Cyclazocine produced $100 \%$ DK selection in pigeons trained to discriminate $1.8 \mathrm{mg} / \mathrm{kg}$ of morphine from saline; subsequently, the ability of naltrexone, I-NANM, and ketamine to antagonize this effect of cyclazocine was studied.

\section{Data Analysis}

The percentage of DK sclections was used as a measure of training drug-like discriminative stimulus effects. To evaluate parallelism of dose-effect curves, a line was fitted by linear regression to log dose - \% DK selections data for each drug, and the statistical significance of slope differences was assessed, using the methods described in Tallarida and Murray [1981].

The incidence of DK selection was defined as follows: number of DK selections (number of doses tested times number of replications). For each pigeon, the incidence of DK selection produced by cyclazocine, I-NANM, and ketamine was calculated. For each of these drugs, the incidence of DK selection was assessed when the drug was administered alone and when it was administered after naltrexone $(0.32$ and $10 \mathrm{mg} / \mathrm{kg}$ ). The Friedman test [Siegel, 1956] was used to evaluate the statistical significance of the effects of naltrexone on the incidence of DK selection.

Selection latency was defined as the time (in sec) between the illumination of the response keys and the occurrence of key selection. Selection latencies were log-transformed prior to statistical analysis by one-factor (i.e., dose) repeated measures analysis of variance [Winer, 1971]. Post hoc comparisons were made using Dunnett's $t$ test.

\section{Drugs}

The compounds used were morphine sulfate, naltrexone hydrochloride, d1-cyclazocine, 1-N-allylnormetazocine hydrochloride, ketamine hydrochloride, and U50,488 methanesulphonate hydrate. dl-Cyclazocine was dissolved in distilled water acidified with lactic acid; all other drugs were dissolved in sterile water. Doses are expressed in the forms described above.

\section{RESULTS Generalization}

Morphine $(5.6 \mathrm{mg} / \mathrm{kg})$ acquired discriminative control over responding in all pigcons; the geometric mean of the number of sessions to criterion (GM-STC) was 55. The accuracy of 

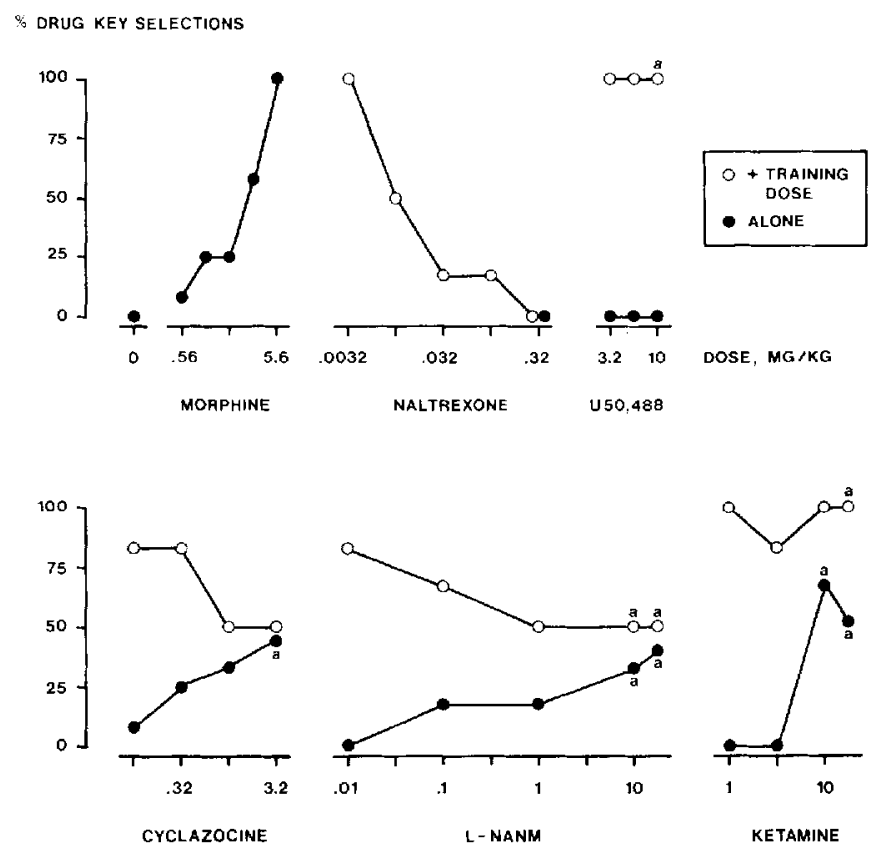

Fig. 1. Discriminative stimulus effects of morphine, naltrexone, U50,488, dl-cyclazocine, l-N-allylnormetazocine (1-NANM), and ketamine alone $(\bullet)$ and combined with the training dose (o) in pigeons ( $n$ $=6$ ) trained to discriminatc betwcen injections of $5.6 \mathrm{mg} / \mathrm{kg}$ of morphine and of saline. Data points that are marked with an "a" were obtained at doses that significantly increased the mcan key-selection latency. Doses of morphine and of $\mathrm{d} l$-cyclazocine when given alone were tested twice. Ordinates: percentage of morphine-key selections; abscissae: IM dose administered $(\mathrm{mg} / \mathrm{kg}), 10 \mathrm{~min}$ before the start of the session (-) or $15 \mathrm{~min}$ before the injection of $5.6 \mathrm{mg} / \mathrm{kg}$ of morphine (0).

the postcriterion discrimination performance was not significantly different between drug and saline sessions $(P>0.05)$, the mean percentage of correct key selections ( \pm 1 SEM) being $92 \pm 1$.

Morphine exerted dose-dependent effects on the percentage of DK selections (Fig. 1). Although the percentage of DK selections was dose-dependently increased by cyclazocine, by 1-NANM, and by ketamine, each of these drugs produced a maximum percentage of DK selections lower than that produced by morphine. Cyclazocine produced a maximum of $45 \%$ at a dose of $3.2 \mathrm{mg} / \mathrm{kg}$, ketamine produce a maximum of $67 \%$ at $10 \mathrm{mg} / \mathrm{kg}$, and $1-\mathrm{NANM}$ produced $40 \%$ DK selections at $18 \mathrm{mg} / \mathrm{kg}$. Cyclazocine was tested twice and produced DK selection in all pigeons during the first and/or the second test. 1-NANM and ketamine were tested once and produced DK selection in three and in four of the six pigeons, respectively.

The log dose-DK selection data obtained with morphine, cyclazocine, 1-NANM, and ketamine could be fitted adequately by straight lines (the correlation coefficients ranged from 0.84 to 0.99 ). For each of the drugs, all data were included in the regression analysis. The slope of the regression line, indicating the amount by which the percentage of DK selections increased per $1 \mathrm{log}$ unit increase of dose, was 87 for morphine. The slope value for cyclazocine (i.e., 23) was significantly lower than the slope value for morphine $(P<0.05)$. The slope value for I-NANM (11) was significantly lower than the slope value for cyclazocine $(P<$ 0.05 ). However, the slope value for ketamine (76) was not significantly different from the slope value for morphine. U50,488 produced exclusively SK selection. The geometric mean 
key selection latency (GM-KSL) was significantly increased from $10 \mathrm{sec}$ (after saline) to 200 sec by $3.2 \mathrm{mg} / \mathrm{kg}$ of cyclizocine, to 72 and $933 \mathrm{sec}$ by 10 and $18 \mathrm{mg} / \mathrm{kg}$ of 1-NANM, respectively, and to 51 and $1,122 \mathrm{sec}$ by 10 and $18 \mathrm{mg} / \mathrm{kg}$ of ketamine, respectively $(P<$ $0.05)$. Note that ketamine produced DK selection exclusively at doses that increased the key selection latency, unlike the other drugs tested.

\section{Antagonism}

Naltrexone completely antagonized the effects of the training dose of morphine, at a dose $(0.32 \mathrm{mg} / \mathrm{kg})$ that failed to induce DK selection when given alone. Whereas cyclazocine and 1-NANM dose-dependently antagonized the effects of the training dose of morphine, the antagonism was less than maximal in that the percentage of DK selections was not reduced further than to $50 \%$. The $\log$ dose-DK selection data obtained with naltrexone, with cyclazocine, and with 1-NANM as pretreatment to the training dose of morphine were fitted adequately by straight lines. The slope value of the regression line was -47 for naltrexone, -26 for cyclazocine, and -12 for I-NANM. The slope of the regression line describing the I-NANM data was significantly lower than the slope value obtained with naltrexone $(P<$ 0.05 ). Neither ketamine nor U50,488 reduced the percentage of DK selections in a monotonic, dose-dependent manner.

\section{Antagonism of Partial Generalization}

The effect of naltrexone on the incidence of DK selection produced by cyclazocine approached statistical significance $(P<0.06)$, as did the effect of naltrexone on 1-NANMinduced DK selection $(P<0.09)$. At a dose of $10 \mathrm{mg} / \mathrm{kg}$, naltrexone reduced the ability of all but the highest dose of cyclazocine and of 1-NANM to produce DK selection (Fig. 2). The incidence of DK sclection observed after ketamine was not significantly affected by naltrexone $(P>0.50)$.

The lowest dose that significantly increased the key selection latency was $3.2 \mathrm{mg} / \mathrm{kg}$ for cyclazocine, $10 \mathrm{mg} / \mathrm{kg}$ for $1-\mathrm{NANM}$, and $10 \mathrm{mg} / \mathrm{kg}$ for ketamine. Naltrexone $(0.32$ and 10 $\mathrm{mg} / \mathrm{kg}$ ) failed to block significantly the selection latency-increasing effects of cyclazocinc, 1-NANM, and ketamine $(P>0.10)$. Note that, in general, naltrexone blocked DK selection primarily when DK selection was produced by doses that did not increase the key selection latency.

\section{Antagonism in High-Training-Dose Pigeons}

The two pigeons for which the training dose of morphine was increased from 5.6 to 18 $\mathrm{mg} / \mathrm{kg}$ met the discrimination criterion at a dose of $10 \mathrm{mg} / \mathrm{kg}$ after 14 (pigeon 1) and 0 (pigeon 2) STC. They met the criterion after 0 STC as the training dose was increased further to 18 $\mathrm{mg} / \mathrm{kg}$. The mean percentage of correct key selections was 100 , both during postcriterion drug sessions and saline sessions.

By increasing the training dose from 5.6 to $18 \mathrm{mg} / \mathrm{kg}$, the dose-effect curve of morphine was shifted to the right (Fig. 3), in a parallel manner. (The slope values were not significantly different.) The $18 \mathrm{mg} / \mathrm{kg}$ training dose of morphine significantly increased the GM-KSL from 17 to $52 \mathrm{sec}(P<0.05)$. Naltrexone antagonized completely the effects of $18 \mathrm{mg} / \mathrm{kg}$ of morphine. In the presence of $0.032 \mathrm{mg} / \mathrm{kg}$ of naltrexone, $18 \mathrm{mg} / \mathrm{kg}$ of morphine produced neither DK selection nor an increase of the key selection latency. The effects of $18 \mathrm{mg} / \mathrm{kg}$ of morphine were antagonized also by cyclazocine and by I-NANM, but not by ketamine. The log dose-DK selection data obtained with naltrexone, cyclazocine, and l-NANM as pretreatment to the $18-\mathrm{mg} / \mathrm{kg}$ training dose of morphine were fitted adequately by straight lines. The slope values of the regression lines were not significantly different. The antagonist effects of cyclazocine were enhanced in the $18 \mathrm{-mg} / \mathrm{kg}$-trained pigeons, but remained less than complete: whereas $0.1 \mathrm{mg} / \mathrm{kg}$ of cyclazocine decreased the percentage of DK selections produced by the 

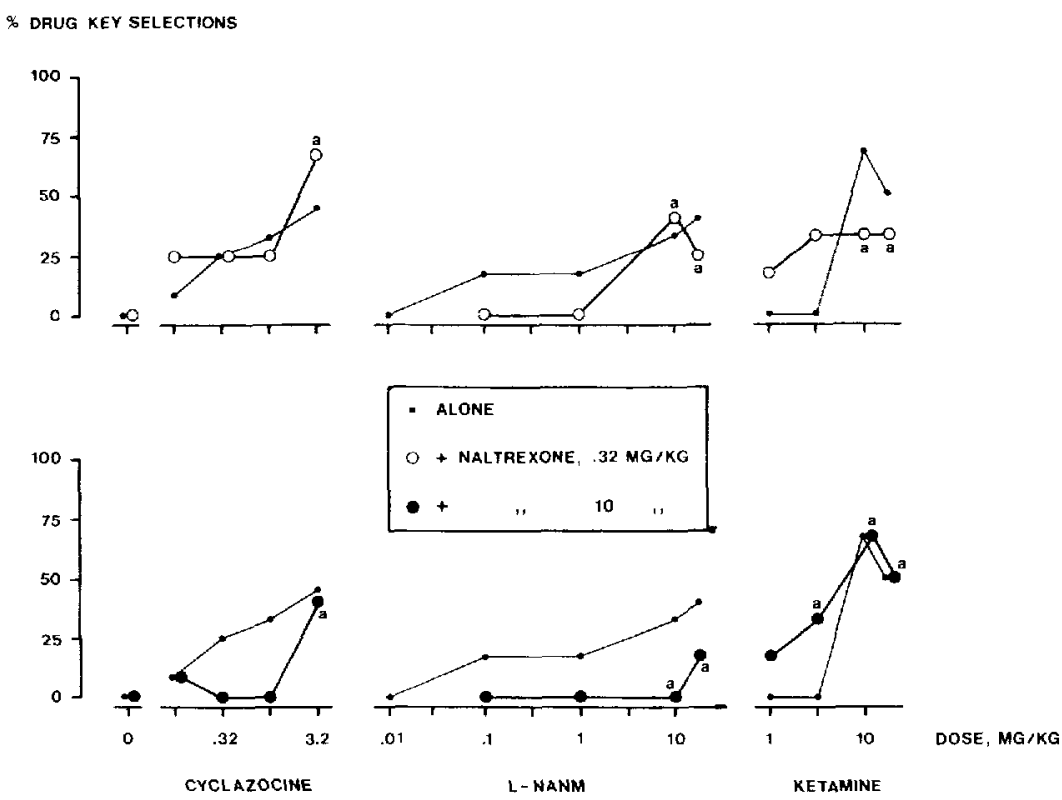

Fig. 2. Discriminative stimulus effects of dl-cyclazocine, l-N-allyl-normetazocine (l-NANM), and ketaminc alone (small filled circles, replotted from Fig. 1) and $15 \mathrm{~min}$ after the injection of $0.32 \mathrm{mg} / \mathrm{kg}$ (open circles, upper panels) or $10 \mathrm{mg} / \mathrm{kg}$ (large filled circles, lower panels) of naltrexone, in pigeons $(\mathrm{n}=6)$ trained to discriminate between injections of $5.6 \mathrm{mg} / \mathrm{kg}$ of morphine and of saline. Data points that are marked with an "a" were obtained at doses that significantly increased the mean key-selection latency. Ordinates: percentage of morphine-key selcctions; abscissae: IM dose administered (mg/kg), 10 min before the start of the test session.

$5.6-\mathrm{mg} / \mathrm{kg}$ training dose of morphine from 100 to 83 , this dose of cyclazocine decreased the effects of the $18-\mathrm{mg} / \mathrm{kg}$ training dose of morphine from 100 to $25 \%$. In the dose-range in which cyclazocine produced antagonism, it produced a maximum of $25 \%$ DK selections when given alone. Whereas 1-NANM antagonized the effects of the training dose of $5.6 \mathrm{mg} / \mathrm{kg}$ of morphine only partially, l-NANM acted as a complete antagonist of $18 \mathrm{mg} / \mathrm{kg}$ of morphine. In the dose range in which l-NANM produced complete antagonism, it failed to induce any DK selection when given alone. However, 1-NANM produced a maximum of $50 \%$ DK selections at a higher dose (i.e., $10 \mathrm{mg} / \mathrm{kg}$ ) that increased the selection latency. Ketamine produced $50 \%$ DK selections in the $18-\mathrm{mg} / \mathrm{kg}$-trained pigeons and failed to antagonize the discriminative stimulus effects of $18 \mathrm{mg} / \mathrm{kg}$ of morphine.

\section{Generalization in Low-Training-Dose Pigeons}

All three pigeons for which the training dose was decreased reached the discrimination criterion both at $3.2 \mathrm{mg} / \mathrm{kg}(\mathrm{GM}-\mathrm{STC}=7)$ and at $1.8 \mathrm{mg} / \mathrm{kg}$ of morphine (GM-STC $=15)$. However, due to time limitations, the planned tests could not be conducted in the pigeon that reached criterion last. In the remaining two pigeons, the mean percentage of correct key selections was $96 \pm 2$ and $83 \pm 12$ during postcriterion saline sessions and drug sessions, respectively.

By decreasing the training dose from 5.6 to $1.8 \mathrm{mg} / \mathrm{kg}$ the dose-effect curve of morphine was shifted to the left (Fig. 4), in a parallel manner. Naltrexone antagonized the effects of 1.8 $\mathrm{mg} / \mathrm{kg}$ of morphine at a dose that was lower than the dose needed to antagonize the effects of 

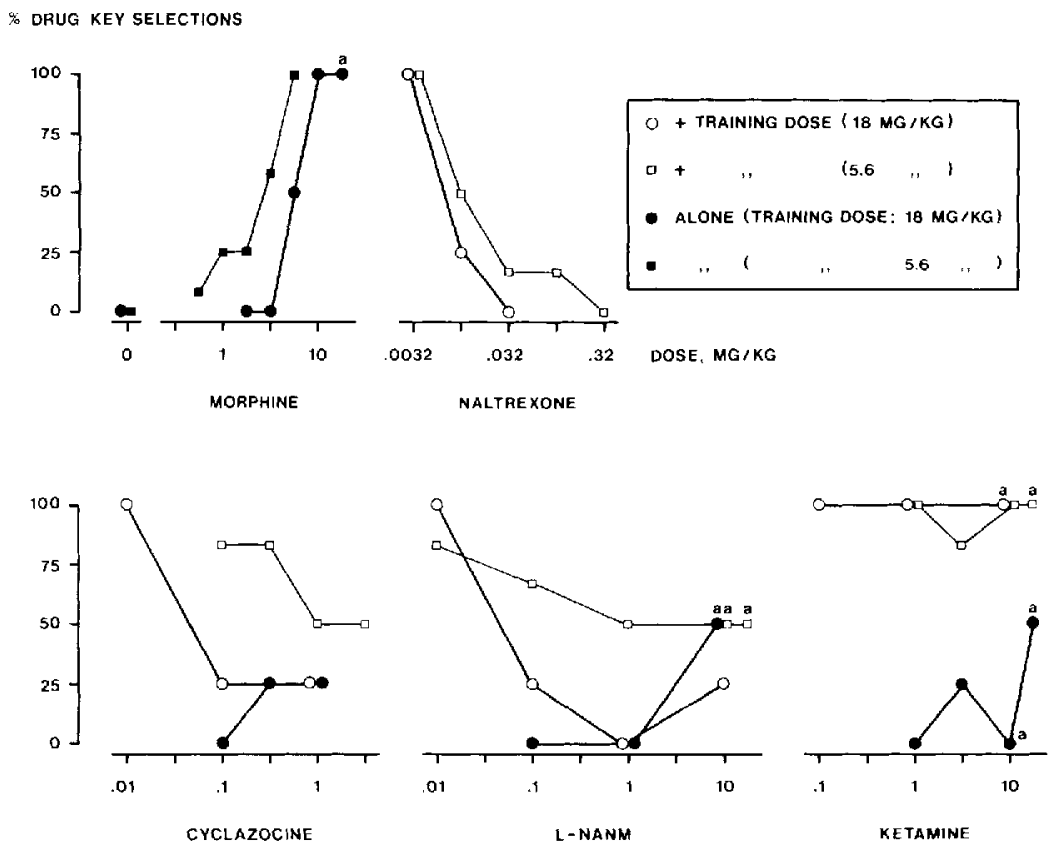

Fig. 3. Discriminative stimulus effects of morphine, naltrexone, dl-cyclazocine, l-N-allylnormetazocinc (1-NANM), and ketaminc alone (filled symbols) and combined with the training dose (open symbols) in pigeons $(\mathrm{n}=2$ ) trained to discriminate between injections of $18 \mathrm{mg} / \mathrm{kg}$ of morphine (circles) and in pigeons $(\mathrm{n}=6$ ) trained to discriminate between injections of $5.6 \mathrm{mg} / \mathrm{kg}$ of morphine and of saline (squares; replotted from Fig. 1). In the two pigeons that were trained to discriminate $18 \mathrm{mg} / \mathrm{kg}$ of morphine from sahne, each dose was tested twice. Data points that are marked with an "a" were obtained at doses that significantly increased the mean key-selection latency. Ordinates: percentage of morphine-key selections; abscissae: IM dose administered $(\mathrm{mg} / \mathrm{kg}), 10 \mathrm{~min}$ before the start of the session (filled symbols) or $15 \mathrm{~min}$ before the injection of the training dose of morphine (open symbols).

$5.6 \mathrm{mg} / \mathrm{kg}$ of morphine. In the $1.8 \mathrm{mg} / \mathrm{kg}$-trained pigeons, the percentage of DK selections was increased dose-dependently by cyclazocine, by 1-NANM, and by ketamine; the data obtained with these drugs could be fitted adequately by straight lines. The slope values for cyclazocine and for ketamine were not significantly different from the slope value for morphine. The slope value for 1-NANM was significantly lower than the slope value for cyclazocine. The maximum percentage of DK selections produced by cyclazocine was increased to its maximum possible value: whereas $1 \mathrm{mg} / \mathrm{kg}$ of cyclazocine did not produce more than $33 \%$ DK selections when the training dose was $5.6 \mathrm{mg} / \mathrm{kg}$, it produced $100 \% \mathrm{DK}$ selections when the training dose was $1.8 \mathrm{mg} / \mathrm{kg}$. Note that $1 \mathrm{mg} / \mathrm{kg}$ of cyclazocine did not significantly affect the key selection latency. In contrast to cyclazocine, neither the ability of 1-NANM nor of ketamine to produce DK selection was increased by a lowering of the training dose from 5.6 to $1.8 \mathrm{mg} / \mathrm{kg}$ of morphine.

\section{Antagonism of Full Generalization Produced by Cyclazocine in Low-Training-Dose Pigeons}

Naltrexone blocked dose-dependently and completely the ability of cyclazocine to produce $100 \%$ DK selections in $1.8 \mathrm{mg} / \mathrm{kg}$-trained pigeons (Fig. 5). The dose of naltrexone that produced complete antagonism $(0.32 \mathrm{mg} / \mathrm{kg})$ was higher than the dose needed to antagonize completely the effects of the $1.8 \mathrm{mg} / \mathrm{kg}$ training dose of morphine $(0.01 \mathrm{mg} / \mathrm{kg}$; 
$\%$ DRUG KEY SELECTIONS

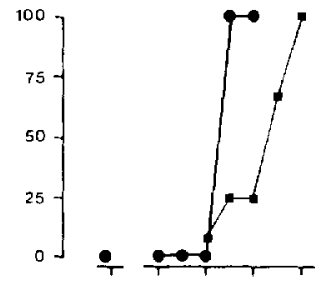

$\begin{array}{lll}0 & .18 & 1.8\end{array}$

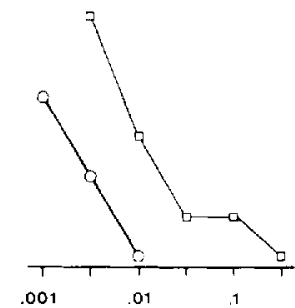

NALTREXONE

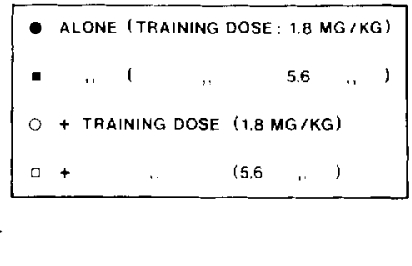

MORPHINE
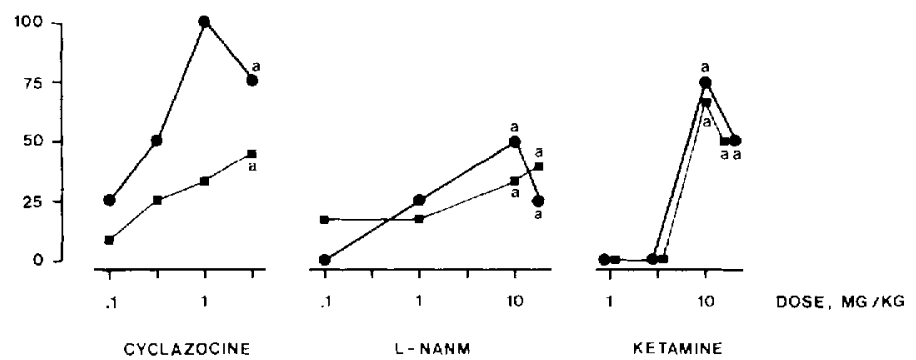

Fig. 4. Discriminative stimulus effects of morphine, naltrexone, dl-cyclazocine, l-N-allylnormetazocine (I-NANM), and ketamine alone (filled symbols) and combined with the training dose (open symbols) in pigeons $(\mathrm{n}-2)$ trained to discriminate between injections of $1.8 \mathrm{mg} / \mathrm{kg}$ of morphine and of saline (circles) and in pigeons $(\mathrm{n}=6)$ trained to discriminate between injections of $5.6 \mathrm{mg} / \mathrm{kg}$ of morphine and of saline (squares; replotted from Fig. 1). In the pigeons that were trained to discriminate $1.8 \mathrm{mg} / \mathrm{kg}$ of morphine from saline, cach dose was tested twice in cach pigcon, except for doses of naltrexone that were tested twice in one pigeon and once in the other pigeon. Data points that are marked with an " $a$ " were obtained at doses that significantly increased the mean key-selection latency. Ordinates: percentage of morphine-kcy selections; abscissae: IM dose administered $(\mathrm{mg} / \mathrm{kg}), 10 \mathrm{~min}$ before the start of the session (filled symbols) or 15 min before the injection of the training dose of morphine (open symbols).

Fig. 4). Furthermore, the slope of the regression line describing the cyclazocine-antagonist effects of naltrexone was significantly shallower than the slope of the morphine-antagonist effects of naltrexone. The ability of cyclazocine to produce $100 \%$ DK selections in $1.8-\mathrm{mg} / \mathrm{kg}$-trained pigeons was antagonized also by I-NANM, in a dose-dependent and complete manner. 1-NANM failed to completely antagonize cyclazocine at a higher dose that produced DK selection and increased the key selection latency when given alone. The slope value of the regression line describing the antagonism of cyclazocine by l-NANM was not significantly different from the slope value for naltrexone. Ketamine blocked only partially the discriminative stimulus effects of cyclazocine, when tested up to a dose that increased the key selection latency.

\section{DISCUSSION}

Cyclazocine produced partial generalization in morphine-discriminating pigeons, a finding that replicates and extends previous observations [e.g., Holtzman, 1983; Colpaert and Janssen, 1984; Paule and Wenger, 1986]. The selective kappa opioid agonist U50,488 failed to produce any morphine key selection. Although initial results obtaincd with kappa agonists 
$\%$ DRUG KEY SELECTIONS
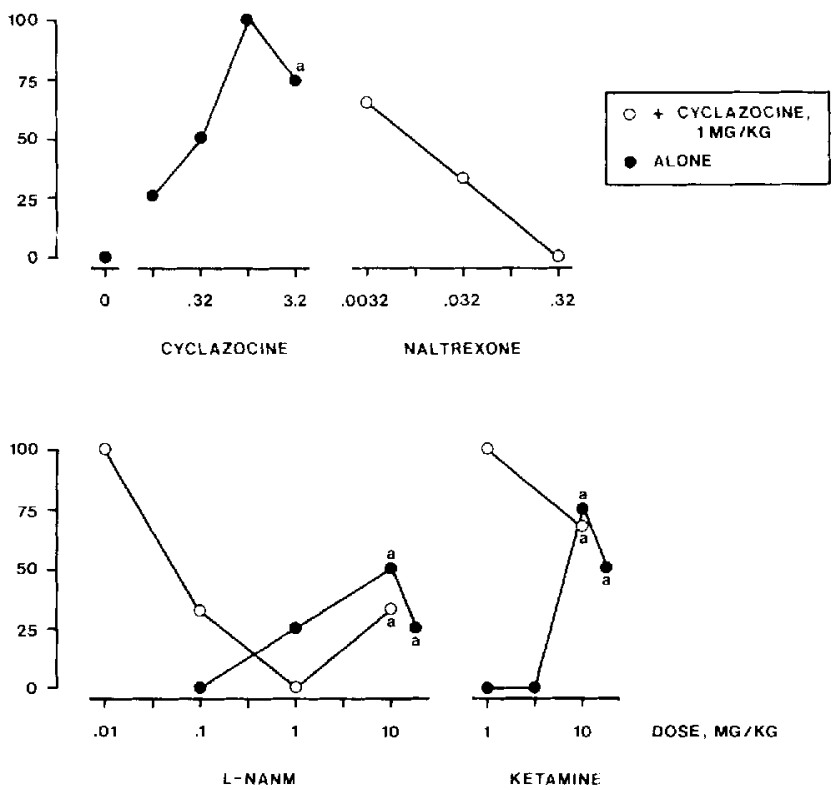

Fig. 5. Discriminative stimulus effects of dl-cyclazocine, naltrexone, $1-\mathrm{N}$-allyl-notmetazocine (1NANM), and ketamine alonc ( $\bullet$ ) and combined with $1 \mathrm{mg} / \mathrm{kg}$ of dl-cyclazocine $(0)$ in pigeons $(\mathrm{n}=2)$ trained to discriminate between injections of $1.8 \mathrm{mg} / \mathrm{kg}$ of morphine and saline. Each dose was tested twice in one pigeon and once in the other pigeon. Data points that are marked with an "a" were obtained at doses that significantly increased the mean key-selection latency. Ordinates: percentage of morphinekey selections; abscissae: IM dose administered $(\mathrm{mg} / \mathrm{kg}), 10 \mathrm{~min}$ before the start of the session $(\bullet)$ or 15 min before the injection of $1 \mathrm{mg} / \mathrm{kg}$ of $\mathrm{dl}$-cyclazocine ( $(0)$.

that were less selective than U50,488 indicated that the pigeon may not be able to discriminate between mu and kappa agonists [Herling and Woods, 1981], more recent results show greater differentiation [Picker and Dykstra, 1987], in agreement with the results of the present study. Like cyclazocine, both 1-NANM and the PCP-like compound kctamine produced partial generalization, in agreement with previous findings in morphine-discriminating pigeons [unpublished observations; Herling et al., 1980].

For cyclazocine, 1-NANM, and ketamine, several predictions, derived from receptor theory, were tested to evaluate the hypothesis that low efficacy at the receptor that mediates the discriminative stimulus effects of the training drug underlies their partial generalization effects.

The generalization gradient of cyclazocine was less steep than the generalization gradient of morphine. The gradient of 1-NANM was shallower than the gradient of cyclazocine. These findings suggest that cyclazocine is less efficacious than morphine and that I-NANM is less efficacious than cyclazocine at the receptor that underlies morphine's discriminative stimulus effects. However, the finding that the slope of the ketamine gradient was not significantly different from the slope of the morphine gradient is not in agreement with the hypothesis that ketamine is a low-efficacy agonist at this receptor.

A low-efficacy agonist should partially antagonize the discriminative stimulus effects of the training drug, in the dose range in which it produces partial agonism. This prediction was verified for cyclazocine and for I-NANM, but not for ketamine. 
The discriminative stimulus effects of a low-efficacy agonist should be blocked by an antagonist. Naltrexone appeared to block the generalization produced by cyclazocine and by l-NANM. However, antagonism was not complete and occurred only at a dose that was higher than the dose needed to block the effects of morphine. This observation may be consistent with receptor theory. The dose-effect curves of a full and of a partial agonist should be shifted an equal amount to the right when combined with the same antagonist. However, the dose-effect curve of a partial agonist is shallower than the dose-effect curve of a full agonist. If, for example, the slope of the dose-effect curve of a partial agonist is ten times less steep than the slope of the dose-effect curve of a full agonist, the lowest dose of an antagonist that reduces the maximum effect of the full agonist by $100 \%$ reduces the maximum effect of the partial agonist by only $10 \%$. Such small reductions of the level of drug-appropriate responding may be difficult to detect reliably, under the conditions of the present experiment. Naltrexone failed to block the effects of ketamine and did not block completely the effects of those doses of cyclazocine and of 1-NANM that increased selection latency.

In accordance with receptor theory, decreasing the apparent sensitivity of the discrimination by increasing the training dose of morphine affected the agonist and antagonist effects of cyclazocine and of l-NANM: both drugs had more antagonist activity and less agonist activity in the dose range in which antagonism was observed. Beyond that dose range, however, 1-NANM still produced substantial generalization, albeit at selection latencyincreasing doses. At the higher training dose of morphine, ketamine did not show antagonist activity, but did show agonist activity at selection latency-increasing doses, similar to its effects at the original training dose. Naltrexone completely antagonized the effects of the higher training dose of morphine.

By decreasing the training dose, the apparent sensitivity of the morphine discrimination was increased. Naltrexone completely blocked the discriminative stimulus effects of the lowered training dose of morphine. The antagonism occurred at lower doses of naltrexone, further evidencing the increased sensitivity of the discrimination. As the training dose of morphine was lowered, the agonist effects of cyclazocine increased, i.e., cyclazocine produced full morphine-appropriate responding that could be blocked completely by naltrexone. However, the agonist effects of I-NANM and of ketamine were not detectably affected by the decrease of the training dose. In the initial part of this study, l-NANM produced partial generalization along a gradient that was shallower than the gradient of cyclazocine, unlike ketamine. Furthermore, as the training dose was increased, l-NANM showed less agonist and more antagonist activity than cyclazocine, unlike ketamine. These observations together suggest that 1-NANM, but not ketamine, has lower efficacy than cyclazocine at the receptor that underlies the morphine discrimination. Although the sensitivity of the discrimination was increased sufficiently for cyclazocine to produce full generalization, the increase may not have been sufficiently large to enable l-NANM to produce a higher level of agonist activity.

If l-NANM has lower efficacy than cyclazocine, I-NANM should block the discriminative stimulus effects of cyclazocine. Indeed, the full gencralization observed with cyclazocine in pigeons trained to discriminate a lowered dose of morphine from saline was antagonized completely by 1-NANM. Beyond the dose range in which a complete blockade was observed, I-NANM failed to act as a full antagonist of cyclazocine and increased the selection latency. Ketamine antagonized the effects of cyclazocine only partially, and only at a dose that increased the selection latency.

Taken together, the results suggest that cyclazocine and 1-NANM produce partial generalization in morphine-discriminating pigeons because they have a lower efficacy than morphine at the receptor that underlies the discriminative stimulus effects of morphine. Furthermore, the efficacy of l-NANM appears to be lower than the cfficacy of cyclazocine. However, the partial generalization observed with ketamine appears to be based on a different mechanism, because: 1) the slope of the ketamine gradient is not shallower than the slope of 
the morphine gradient; 2) the partial generalization could not be blocked by naltrexone; 3) ketamine failed to antagonize morphine, even as the training dose of morphine was increased; 4) ketamine did not produce more drug-appropriate responding as the training dose of morphine was decreased; 5) ketamine failed to antagonize the effects of cyclazocine; and 6) the agonist effects of ketamine occurred only at selection latency-increasing doses. These results suggest that partial generalization may occur in morphine-discriminating animals through mechanisms that perhaps differ from the receptor mechanism underlying the discriminative stimulus effects of morphine. Indeed, this different, nonopioid mechanism may be responsible not only for the morphine-appropriate responding produced by ketamine, but also for the morphine-appropriate responding produced by selection latency-increasing doses of cyclazocine and of I-NANM, because the agonist effects of these doses were not blocked completely by naltrexone and did not decrease as the training dose was increased. Conceivably, a disruption of discriminative behavior may result in intermediate levels of drugappropriate responding [e.g., Koek and Slangen, 1984]. Given that cyclazocine, I-NANM, and ketamine all have PCP-like behavioral effects [e.g., they all substitute completely for PCP in PCP-discriminating pigeons (Koek and Woods, unpublished observations)] and given the ability of PCP-like drugs to reduce the accuracy of discriminative bchavior [c.g., Kock and Woods, 1986; Moerschbaecher et al., 1984; Picker and Dykstra, 19887, it may be suggested that partial generalization, at selection latency-increasing doses, is perhaps caused by a disruption of discriminative behavior.

In summary, the results obtained here agree with the suggestion that partial generalization indicates a low efficacy at the receptor that mediates the discriminative stimulus effects of the training drug [Colpaert, 1986, 1988; Colpaert and Janssen, 1984; Holtzman, 1983; Holtzman and Locke, 1988; Woods et al., 1988], with the restriction, however, that partial generalization may perhaps be produced also through other, less well-characterized mechanisms. Preliminary results suggest that PCP-like drugs may produce partial generalization not only in morphine-discriminating pigcons, but also in fentanyl-discriminating rats [Koek and Colpaert, unpublished observations]. In conclusion, the results presented here stress the importance of a detailed analysis of partial generalization effects, guided by receptor theory, to establish their underlying mechanism.

\section{ACKNOWLEDGMENTS}

The authors would like to thank Dr. A.J. Bertalmio and Dr. G. Winger for stimulating discussions and Dr. F.C. Colpaert for his critical reading of an earlier draft of this manuscript. This work was supported by a North Atlantic Treaty Organization Science Fellowship and a Constantijn and Christiaan Huygens Career Development Award to Wouter Koek, received from the Netherlands Organization for the Advancement of Pure Research (Z.W.O.) and by U.S. Public Health Service grant DA-05325.

\section{REFERENCES}

Colpaert, F.C.: Drug discrimination: Behavioral, pharmacological and molecular mechanisms of discriminative drug effects. In Goldberg, S. and Stolerman, I.P. (eds.): "Behavioral Analysis of Drug Dependence." New York: Academic Press, 1986, pp. 161-193.

Colpaert, F.C.: Intrinsic activity and discriminative effects of drugs. In Colpaert, F.C. and Balster, R.L. (eds.): "Transduction Mechanisms of Drug Stimuli." Berlin: Springer-Verlag, 1988, pp. $154-160$.

Colpaert, F.C. and Janssen, P.A.J.: Agonist and antagonist effects of prototype opiate drugs in rats discriminating fentanyl from saline: Characteristies of partial generalization. J. Pharmacol. Exp. Ther. 230:193-199, 1984. 
Colpaert, F.C., Niemegeers, C.J.E., and Janssen, P.A.J.; Factors regulating drug cue sensitivity: The effect of training dose in fentanyl-saline discrimination. Neuropharmacology 19:705-713, 1980.

Colpaert, F.C., Niemegecrs, C.J.E., and Janssen, P.A.J.: A drug discrimination analysis of lysergic acid diethylamide (LSD): In vivo agonist and antagonist effects of purported 5-hydroxytryptamine antagonists and of pirenperone, a LSD-antagonist. J. Pharmacol. Exp. Ther. 221:206-214, 1982.

Essman, W.D. and Woods, J.H.: Discriminative stimulus and receptor binding properties of kappa agonists in the pigeon. Pharmacol. Biochem. Behav. 25:305, 1986.

Herling, S. and Woods, J.H.: Discriminative stimulus effects of narcotics: Evidence for multiple receptor-mediated actions. Life Sci. 28:1571-1584, 1981.

Herling, S., Coale, E.H., Valentino, R.J., Hein, D.W., and Woods, J.H.: Narcotic discrimination in pigeons. J. Pharmacol. Exp. Ther. 214:139-146, 1980.

Holtzman, S.G.: Discriminative stimulus properties of opioids in the rat and squirrel monkey. In Colpaert, F.C. and Slangen, J.L. (eds.): "Drug Discrimination: Applications in CNS Pharmacology." Amsterdam: Elsevier Biomedical Press, 1982, pp. 17-34.

Holtzman, S.G.: Discriminative stimulus properties of opioid agonists and antagonists. In Cooper, S.J. (ed.): "Theory in Psychopharmacology." London: Academic Press, 1983, Vol. 2, pp. 1-45.

Holtzman, S.G. and Locke, K.W.: Neural mechanisms of drug stimuli: Experinental approaches. In Colpacrt, F.C. and Balster, R.L. (eds.): "Transduction Mechanisms of Drug Stimuli." Berlin: Springer-Verlag, 1988, pp. 139-153.

Kenakin, T.P.: Pharmacologic analysis of drug-receptor interaction. New York: Raven Press, 1987.

Koek, W. and Slangen. J.L.: The role of fentanyl training dose and of the alternative stimulus condition in drug generalization. Psychopharmacology 76:149-156, 1982.

Koek, W. and Slangen, J.L.: Extcrnal stimulus control in a "drug discrimination" procedure: Drug effects and interanimal variation. Psychopharmacology 82:168-173, 1984.

Koek, W. and Woods, J.H.: Response repetition in pigeons: Pharmacological and behavioral specificity. Psychopharmacology 90:475-481, 1986.

Moerschbaecher, J.M., Mastropaolo, I., Winsauer, P.J., and Thompson, D.M.: Effects of opioids on accuracy of a fixed-ratio discrimination in monkeys and rats. J. Pharmacol. Exp. Ther. 230:541-549, 1984.

Paule, M.G. and Wenger, G.R.: Morphine discrimination in the pigeon using a color tracking procedure. Pharmacol. Biochem. Behav. 24:597-604, 1986.

Picker, M. and Dykstra, L.A.: Comparison of the discriminative stimulus properties of U50,488 and morphine in pigeons. J. Pharmacol. Exp. Ther. 243:938-945, 1987.

Picker, M. and Dykstra, L.A.: Differential effects of opioid and nonopioid analgesics on conditional discriminations in pigeons. Psychopharmacology 94:405-411, 1988.

Siegel, S.: "Nonparametric Statistics." New York: McGraw-Hill, 1956, pp. 166-172.

Tallarida, R.J. and Murray, R.B.: Manual of pharmacologic calculations. New York: Springer-Verlag, 1981, pp. 11-12.

Winer, B.J.: Statistical Principles in Experimental Design, 2nd edition. New York: McGraw-Hill, 1971, pp. 261-305.

Woods, J.H., Bertalmio, A.J., Young, A.M., Essman, W.D., and Winger, G.: Receptor mechanisms of opioid drug discrimination. In Colpaerl, F.C. and Balster, R.L. (eds.): "Transduction Mechanisms of Drug Stimuli.' Berlin: Springer-Verlag, 1988, pp. 93-106. 